\title{
Self-thinning in four pine species: an evaluation of potential climate impacts
}

\author{
Pau Brunet-Navarro ${ }^{1}$ (1) Frank J. Sterck ${ }^{1}$. Jordi Vayreda ${ }^{2,3}$. \\ Jordi Martinez-Vilalta ${ }^{2,3}$ • Godefridus M.J. Mohren ${ }^{1}$
}

Received: 12 May 2015 / Accepted: 22 September 2016/Published online: 17 October 2016

(C) The Author(s) 2016. This article is published with open access at Springerlink.com

\begin{abstract}
- Key message Self-thinning lines are species- and climatespecific, and they should be used when assessing the capacity of different forest stands to increase biomass/carbon storage. - Context The capacity of forests to store carbon can help to mitigate the effects of atmospheric $\mathrm{CO}_{2}$ rise and climate change. The self-thinning relationship (average size measure $\sim$ stand density) has been used to identify the potential capacity of biomass storage at a given density and to evaluate the effect of stand management on stored carbon. Here, a study that shows how the self-thinning line varies with species and climate is presented.

- Aims Our main objective is thus testing whether species identity and climate affect the self-thinning line and therefore the potential amount of carbon stored in living biomass.
\end{abstract}

Handling Editor: Andreas Bolte

Frank J. Sterck

Frank.Sterck@wur.nl

Pau Brunet-Navarro

p.brunet.n@gmail.com

Jordi Vayreda

j.vayreda@creaf.uab.cat

Jordi Martinez-Vilalta

jordi.martinez.vilalta@uab.cat

Godefridus M.J. Mohren

Frits.Mohren@wur.nl

1 Forest Ecology and Forest Management Group, Department of Environmental Sciences, Wageningen University, Droevendaalsesteeg 3, 6708 PB Wageningen, The Netherlands

2 CREAF, 08193 Cerdanyola del Vallès, Spain

3 Univ. Autònoma de Barcelona, 08193 Cerdanyola del Vallès, Spain
- Methods The Ecological and Forest Inventory of Catalonia was used to calculate the self-thinning lines of four common coniferous species in Catalonia, NE Iberian Peninsula (Pinus halepensis, Pinus nigra, Pinus sylvestris and Pinus uncinata). Quadratic mean diameter at breast height was chosen as the average size measure. The self-thinning lines were used to predict the potential diameter at a given density and study the effect of environmental variability.

- Results Species-specific self-thinning lines were obtained. The self-thinning exponent was consistent with the predicted values of $-3 / 2$ and $-4 / 3$ for mass-based scaling for all species except $P$. sylvestris. Species identity and climatic variability within species affected self-thinning line parameters.

- Conclusion Self-thinning lines are species-specific and are affected by climatic conditions. These relationships can be used to refine predictions of the capacity of different forest stands to increase biomass/carbon storage.

Keywords Self-thinning rule · Quadratic mean diameter · Stand density $\cdot$ Stand dynamics $\cdot$ Forest management $\cdot$ Carbon sequestration

\section{Introduction}

Forests store approximately $45 \%$ of terrestrial carbon, constitute around $50 \%$ of terrestrial primary production and can sequester large amounts of carbon annually (Bonan 2008; Pan et al. 2011) and thus mitigate the rise of atmospheric $\mathrm{CO}_{2}$ and global warming. Carbon sequestration is particularly high in young, secondary forests, which dominate many areas in the temperate zone (Bonan 2008; Pan et al. 2011). In secondary forests, developing trees accumulate mass, particularly in the stem. However, while growing taller and bigger, trees in secondary forests may compete strongly for available 
resources such as light, water and nutrients. Under conditions of limited resource availability, weaker trees may become suppressed and ultimately die. In other words, such forests will gradually be dominated by fewer larger trees.

The concept of self-thinning lines (STLs) predicts a power relationship between tree density and average tree size as closed stands develop. In comparison with forest yield and models, which reports tree size changes (volume or basal area) over time, STLs do not consider time explicitly. In STLs, tree size has been described by using different variables, including mass (Yoda et al. 1963), mean stem diameter (Reineke 1933), or tree height (Anfodillo et al. 2013). In logarithmic scales, STLs are represented by a straight line. Since its first mention by Reineke (1933), it has been acknowledged that the slope of this line may vary between species. However, a possible constant value of this slope has been widely discussed ever since (Weller 1987; Lonsdale 1990; Enquist et al. 1998). Early studies used geometric models and predicted slope values of $-3 / 2$ when tree mass is used as the size measure (Yoda et al. 1963). The slope value was even considered a universal constant and referred to as the 'selfthinning rule' (Westoby 1984). Later studies (West et al. 1997; Enquist et al. 1998) used metabolic scaling theory and predicted slope values of $-4 / 3$. Field studies suggested that the slope may not be a universal constant and may vary between species (Pretzsch 2006), environmental conditions (Deng et al. 2006), or due to biotic interactions (Zhang et al. 2011).

Forest stands that differ in growing conditions are expected to differ in the intercept of the STL (Palahi et al. 2003; Deng et al. 2006). In terms of mass-based scaling, this implies that some species can accumulate more carbon per forest area than others, and forests may accumulate larger amounts of carbon when resources are less limiting (e.g. Vayreda et al. 2012a). It is well known, for example, that at a given stand density forest trees in relatively rainy climates become larger than in relatively dry conditions (Ryan and Yoder 1997). From this, the development of forest stands of different species or of the same species but in different climates could be expected to differ in the intercept of the STL, but not necessarily in the slope. This would make self-thinning line estimations a useful tool to predict the potential of forest stands to accumulate carbon and to compare their role in carbon sequestration. If STLs are sensitive to species and climate conditions, they could be used as a tool to assess climate change adaptation and mitigation strategies. The STL concept could be used as a predictive framework to characterize the potential of current forest stands under specific climate conditions for accumulating carbon in future climate scenarios and could be used to develop strategies to maximize carbon stocks to mitigate climate change effects (Luyssaert et al. 2011).

In this study, STLs of four coniferous tree species were investigated over a wide climate and altitudinal gradient in the north-east of the Iberian Peninsula. First, STLs were fitted to see whether they follow the predicted slope of $-1 / 2$ or $-4 / 9$ for mean stem diameter, which is consistent with a slope of $-3 / 2$ and $-4 / 3$ for mass (see Sect. 2.1). Climate was also expected to impact self-thinning patterns (slope and intercept) across and within species in different ways, since the four species studied are adapted to different climatic conditions and grow under different environmental conditions. Particularly, populations at the lowest altitudes, where the warmest and driest conditions occur, were expected to suffer from water stress and consequently to have lower intercepts than other populations. At the higher altitudinal end, the pattern may be reversed, as forest stands would benefit from relatively low temperatures and greater water availability.

\section{Materials and methods}

\subsection{Self-thinning line}

The self-thinning relationship is usually described by the following equation:

$S=k N^{-a}$

where $S$ is the average size measure (e.g. in biomass $(\mathrm{kg})$, height (m) or stem diameter $(\mathrm{cm})), N$ is the stand density (trees $\mathrm{ha}^{-1}$ ), $k$ has the same dimension and unit as $S$ and $a$ is a non-dimensional slope parameter. In logarithmic form, this equation becomes,

$\log (S)=\log (k)-a \log (N)$

The slope of this equation (parameter $a$ in Eqs. 1 and 2) can be predicted from biophysical scaling relationships (e.g. Solbrig et al. 1980; Enquist et al. 1998). For mean tree biomass, slopes of $-3 / 2$ and $-4 / 3$ have been predicted. Under the same assumptions as used by Begon et al. (1996), when using stem diameter on the $y$-axis, these slopes translate into slopes of $-1 / 2$ and $-4 / 9$, respectively. Empirical tests of these slopes are not yet conclusive, but available data shows that most slopes measured empirically are around these two theoretical values (Weller 1987).

\subsection{Study area and selected species}

The selected area for this study is Catalonia, in the north-east of Spain (Fig. 1b). This area covers a wide range in altitude (from sea level to $>3000 \mathrm{~m}$ above sea level), annual mean temperature $\left(0.0-17.3{ }^{\circ} \mathrm{C}\right)$ and annual precipitation (335$1594 \mathrm{~mm}$ ) in a relatively small area $\left(32,000 \mathrm{~km}^{2}\right)$ (Ninyerola et al. 2000). In the present study, the four most abundant pine species were selected because each species was represented by more than 350 plots in the Ecological and Forestry Inventory of Catalonia (IEFC; see next section) and provided a sufficient 
Fig. 1 Study area. a Distribution of the four pine species studied in Catalonia. b Catalonia location in Europe (modified from Kempeneers et al. (2011))

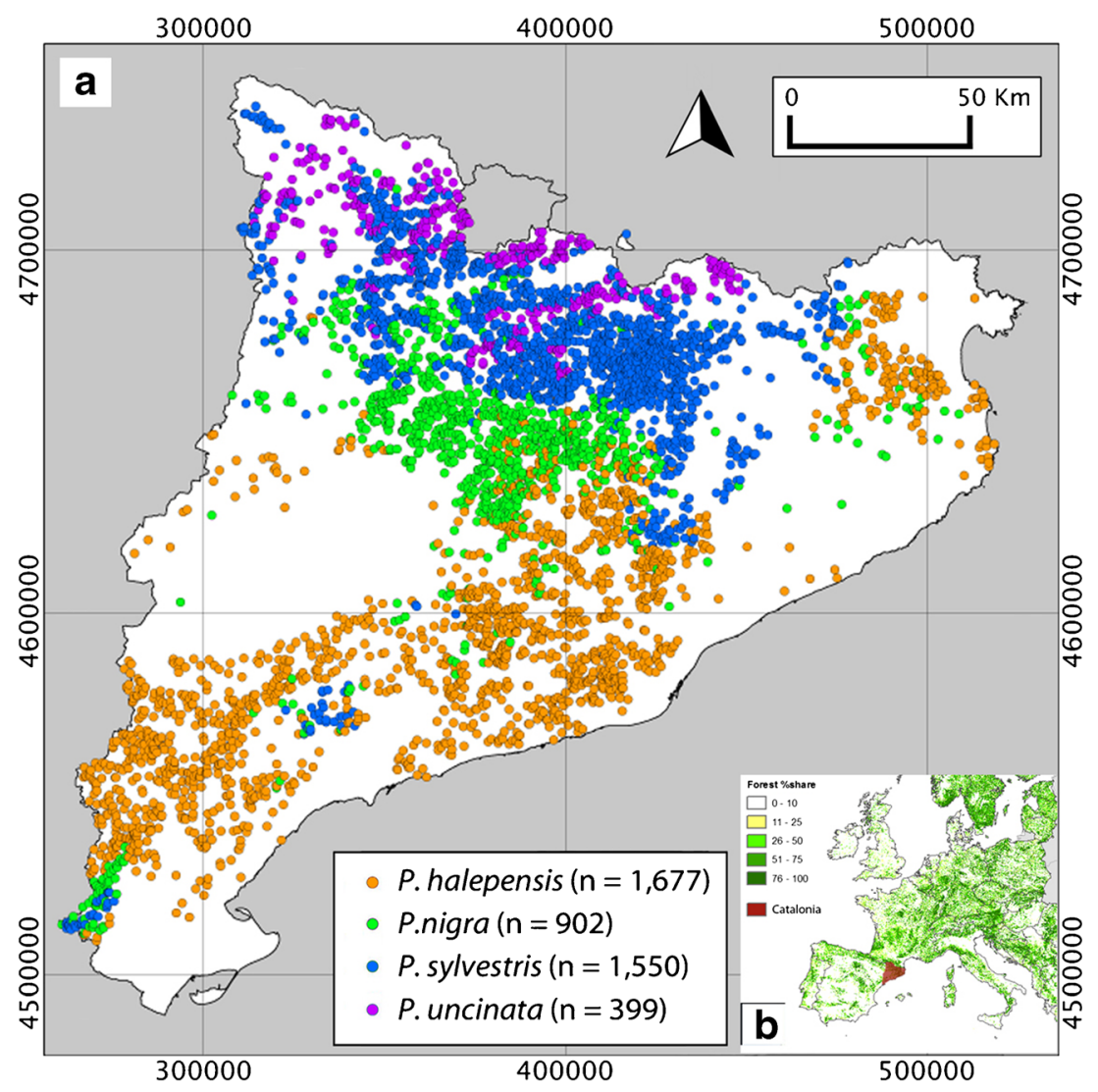

statistical basis to test for differences in scaling relationships (Fig. 1a). The altitudinal variation of Catalonia, especially due to the Pyrenees, creates a wide climate gradient in a relatively small area, with colder and wetter conditions towards higher altitudes. The four studied pine species are abundant in the study area, but they occupy very different areas in Catalonia (Barbero et al. 1998): Pinus halepensis is only present in Mediterranean coastal zones ( $<600 \mathrm{~m}$ above sea level), Pinus nigra also occurs in mid elevations (600-1000 m) in mountainous Mediterranean areas, Pinus sylvestris occupies higher elevations $(800-1500 \mathrm{~m})$ on Mediterranean mountain tops and also in the Pyrenees, and Pinus uncinata is restricted to high elevations $(>1400 \mathrm{~m})$ in the Pyrenees.

\subsection{Data selection}

STLs were estimated for each of the selected species by using the online available IEFC (http://natura.uab.es/mirabosc/), conducted by Centre for Ecological Research and Forestry Applications (CREAF) between 1988 and 1998. This inventory consists of 10,644 plots selected randomly from all the forested area in Catalonia, at a density of $\sim 1$ plot $\mathrm{km}^{-2}$. Plots were circular with a 10-m radius, and sampled forests had different age structures. For this study, monospecific plots (where a single species represented at least $80 \%$ of the total basal area) of the four pines were selected, including 1677 plots for P. halepensis, 902 plots for P. nigra, 1550 plots for P. sylvestris and 399 plots for P. uncinata (Table 1, Fig. 1). All trees with DBH $>5 \mathrm{~cm}$ were sampled in each plot (see IEFC website for additional details on the inventory). For each plot, the present study used tree density (trees $\mathrm{ha}^{-1}$ ) and quadratic mean diameter at breast height (QMD) $(\mathrm{cm})$ to estimate the STL. For the purpose of tree density and QMD calculations, non-target species within a selected plot were included and treated as target species. Annual precipitation ( $\mathrm{mm}$ ) (rain and snow melt) and mean annual temperature $\left({ }^{\circ} \mathrm{C}\right)$ data for each plot was extracted from the Digital Climatic Atlas of Catalonia (Ninyerola et al. 2000) which used data from meteorological stations.

Subsets of plots were selected to estimate the STLs. The first criterion was omitting plots with very low stem density, where self-thinning was unlikely to occur due to low competition between individuals. The minimum stand density at which self-thinning was expected to occur was estimated individually for each species by using the segmented function in the segmented $\mathrm{R}$ package (version 0.5-1.4), using 10-base logarithms. The initial breakpoint guess needed in this function was 2.5 for all species.

Secondly, the range of densities present for each species was divided into intervals of 50 trees $\mathrm{ha}^{-1}$ (Fig. 2). Within each of these intervals, we assumed that only the plots with the highest QMD were subject to self-thinning; the others still 
Table 1 Summary of the monospecific sampled plots extracted from the IEFC inventory

\begin{tabular}{|c|c|c|c|c|c|c|c|c|c|c|c|c|c|c|}
\hline \multirow[t]{2}{*}{ Species } & \multirow[t]{2}{*}{$\mathrm{DC}$} & \multirow[t]{2}{*}{$n$} & \multicolumn{3}{|l|}{$\mathrm{N}$} & \multicolumn{5}{|l|}{$\mathrm{P}$} & \multicolumn{4}{|l|}{$\mathrm{T}$} \\
\hline & & & Min & Max & Avg & $\mathrm{SD}$ & Min & Max & Avg & SD & Min & Max & Avg & $\mathrm{SD}$ \\
\hline \multirow[t]{9}{*}{ P. halepensis } & {$[5-10)$} & 99 & 169 & 4441 & 1187.9 & 872.3 & 375 & 875 & 560.4 & 127.0 & 12.5 & 16.5 & 13.9 & 0.9 \\
\hline & {$[10-15)$} & 687 & 57 & 3825 & 941.4 & 529.0 & 375 & 875 & 571.2 & 114.4 & 11.5 & 16.5 & 13.9 & 1.0 \\
\hline & {$[15-20)$} & 621 & 75 & 2384 & 673.7 & 338.7 & 375 & 1025 & 599.5 & 105.7 & 11.5 & 16.5 & 13.9 & 0.9 \\
\hline & {$[20-25)$} & 202 & 48 & 1515 & 469.3 & 254.4 & 375 & 875 & 629.0 & 108.7 & 11.5 & 16.5 & 13.8 & 1.1 \\
\hline & {$[25-30)$} & 57 & 92 & 830 & 376.7 & 161.3 & 425 & 825 & 647.8 & 86.1 & 11.5 & 15.5 & 13.7 & 1.1 \\
\hline & {$[30-35)$} & 10 & 107 & 505 & 348.7 & 128.8 & 425 & 825 & 655.0 & 113.5 & 11.5 & 14.5 & 13.4 & 1.1 \\
\hline & {$[35-40)$} & 1 & 158 & 158 & 158.0 & - & 525 & 525 & 525.0 & - & 13.5 & 13.5 & 13.5 & - \\
\hline & {$[40-45)$} & 0 & - & - & - & - & - & - & - & - & - & - & - & - \\
\hline & {$[45-50)$} & 0 & - & - & - & - & - & - & - & - & - & - & - & - \\
\hline \multirow[t]{9}{*}{ P. nigra } & {$[5-10)$} & 46 & 183 & 6114 & 2109.2 & 1474.7 & 475 & 975 & 692.4 & 82.5 & 8.5 & 13.5 & 11.8 & 0.9 \\
\hline & {$[10-15)$} & 423 & 218 & 4844 & 1427.2 & 731.7 & 475 & 975 & 696.6 & 67.7 & 9.5 & 14.5 & 12.1 & 0.8 \\
\hline & [15-20) & 280 & 70 & 2691 & 878.2 & 455.0 & 475 & 975 & 698.0 & 72.6 & 9.5 & 14.5 & 12.1 & 0.9 \\
\hline & {$[20-25)$} & 96 & 94 & 1391 & 594.7 & 278.2 & 475 & 975 & 713.0 & 81.4 & 8.5 & 14.5 & 12.1 & 1.3 \\
\hline & {$[25-30)$} & 40 & 53 & 955 & 422.2 & 207.7 & 575 & 925 & 726.3 & 83.6 & 8.5 & 14.5 & 12.5 & 1.7 \\
\hline & {$[30-35)$} & 8 & 40 & 638 & 344.6 & 190.2 & 625 & 925 & 756.3 & 113.2 & 8.5 & 14.5 & 11.6 & 2.1 \\
\hline & {$[35-40)$} & 7 & 178 & 488 & 343.0 & 114.5 & 625 & 875 & 767.9 & 88.6 & 8.5 & 13.5 & 11.2 & 2.0 \\
\hline & {$[40-45)$} & 2 & 127 & 162 & 144.5 & 24.7 & 425 & 725 & 575.0 & 212.1 & 11.5 & 14.5 & 13.0 & 2.1 \\
\hline & {$[45-50)$} & 0 & - & - & - & - & - & - & - & - & - & - & - & - \\
\hline \multirow[t]{9}{*}{ P. sylvestris } & {$[5-10)$} & 27 & 273 & 4974 & 2001.4 & 1168.6 & 675 & 1225 & 873.1 & 109.6 & 7.5 & 12.5 & 10.2 & 1.4 \\
\hline & {$[10-15)$} & 412 & 93 & 4317 & 1310.1 & 695.8 & 525 & 1225 & 866.1 & 106.3 & 5.5 & 13.5 & 10.4 & 1.5 \\
\hline & [15-20) & 627 & 73 & 3896 & 970.4 & 465.6 & 575 & 1175 & 868.3 & 102.6 & 5.5 & 13.5 & 10.0 & 1.6 \\
\hline & {$[20-25)$} & 300 & 80 & 1747 & 716.1 & 314.4 & 625 & 1275 & 887.8 & 106.1 & 4.5 & 13.5 & 9.4 & 1.6 \\
\hline & {$[25-30)$} & 121 & 147 & 1413 & 641.0 & 252.0 & 625 & 1275 & 895.7 & 101.4 & 4.5 & 13.5 & 8.9 & 1.8 \\
\hline & {$[30-35)$} & 43 & 89 & 795 & 463.6 & 172.8 & 625 & 1175 & 904.1 & 109.8 & 4.5 & 12.5 & 8.7 & 1.9 \\
\hline & {$[35-40)$} & 15 & 192 & 678 & 399.7 & 152.1 & 675 & 1125 & 928.3 & 109.3 & 7.5 & 12.5 & 8.8 & 1.4 \\
\hline & {$[40-45)$} & 3 & 214 & 597 & 430.0 & 196.1 & 925 & 1025 & 958.3 & 57.7 & 4.5 & 10.5 & 8.2 & 3.2 \\
\hline & {$[45-50)$} & 2 & 225 & 421 & 323.0 & 138.6 & 925 & 925 & 925.0 & 0.0 & 8.5 & 8.5 & 8.5 & 0.0 \\
\hline \multirow[t]{9}{*}{ P. uncinta } & {$[5-10)$} & 9 & 254 & 4151 & 1714.8 & 1358.6 & 975 & 1275 & 1125.0 & 86.6 & 6.5 & 9.5 & 7.6 & 0.9 \\
\hline & {$[10-15)$} & 69 & 108 & 4436 & 1572.5 & 923.3 & 825 & 1275 & 980.8 & 111.0 & 4.5 & 10.5 & 6.7 & 1.5 \\
\hline & [15-20) & 123 & 195 & 2915 & 1176.5 & 508.6 & 675 & 1225 & 956.3 & 105.3 & 4.5 & 9.5 & 6.2 & 1.2 \\
\hline & {$[20-25)$} & 112 & 148 & 2089 & 868.2 & 347.7 & 675 & 1275 & 970.5 & 108.8 & 4.5 & 9.5 & 6.0 & 1.3 \\
\hline & {$[25-30)$} & 64 & 183 & 1210 & 654.1 & 247.6 & 825 & 1225 & 993.8 & 104.8 & 4.5 & 7.5 & 5.6 & 1.1 \\
\hline & {$[30-35)$} & 15 & 55 & 1055 & 521.9 & 267.2 & 925 & 1225 & 1018.3 & 120.8 & 4.5 & 7.5 & 5.3 & 1.1 \\
\hline & {$[35-40)$} & 3 & 143 & 584 & 323.7 & 231.0 & 975 & 1125 & 1025.0 & 86.6 & 4.5 & 6.5 & 5.2 & 1.2 \\
\hline & {$[40-45)$} & 4 & 108 & 525 & 286.3 & 175.9 & 975 & 1225 & 1112.5 & 103.1 & 4.5 & 4.5 & 4.5 & 0.0 \\
\hline & {$[45-50)$} & 0 & - & - & - & - & - & - & - & - & - & - & - & - \\
\hline
\end{tabular}

$D C$ diameter class (cm), $n$ number of plots, $N$ tree density (trees ha ${ }^{-1}$ ), $P$ precipitation $(\mathrm{mm}), T$ temperature $\left({ }^{\circ} \mathrm{C}\right)$, Min minimum value, Max maximum value, $A v g$ average value, $S D$ standard deviation

had space to growth. The selection criterion used was the 95th percentile of plots with the highest QMD within each of the density intervals. This criterion is arbitrary, but it provided a sufficient sample of plots of each species to allow statistical estimation of the STL and also allowed comparison of STLs between species. STLs were thus estimated by using 73 plots for $P$. halepensis, 87 plots for P. nigra, 109 plots for $P$. sylvestris and 50 plots for $P$. uncinata.

\subsection{Statistical analysis}

After log-transforming the QMD and density for each plot, the STL and its standard error were calculated for each species with a linear model by using the $l m$ function in $\mathrm{R}$ software ( $\mathrm{R}$ Core Team). Results were retransformed. The regression was estimated by using the ordinary least squares. The STLs were also calculated by using the major axis method to be able to 
Fig. 2 Self-thinning lines for the four pine species studied, estimated from the QMD and stand density relationships of monospecific stands. Selfthinning lines were calculated for each species based on the plots (the coloured ones) with the highest QMD values (95\% quantile) for successive density bins (100 trees ha $\left.{ }^{-1}\right)$. Data were log-transformed, and for selfthinning calculations, only plots with $\log$ (density) $>2.5$ (equivalent to 316 trees $\mathrm{ha}^{-1}$ ) were used
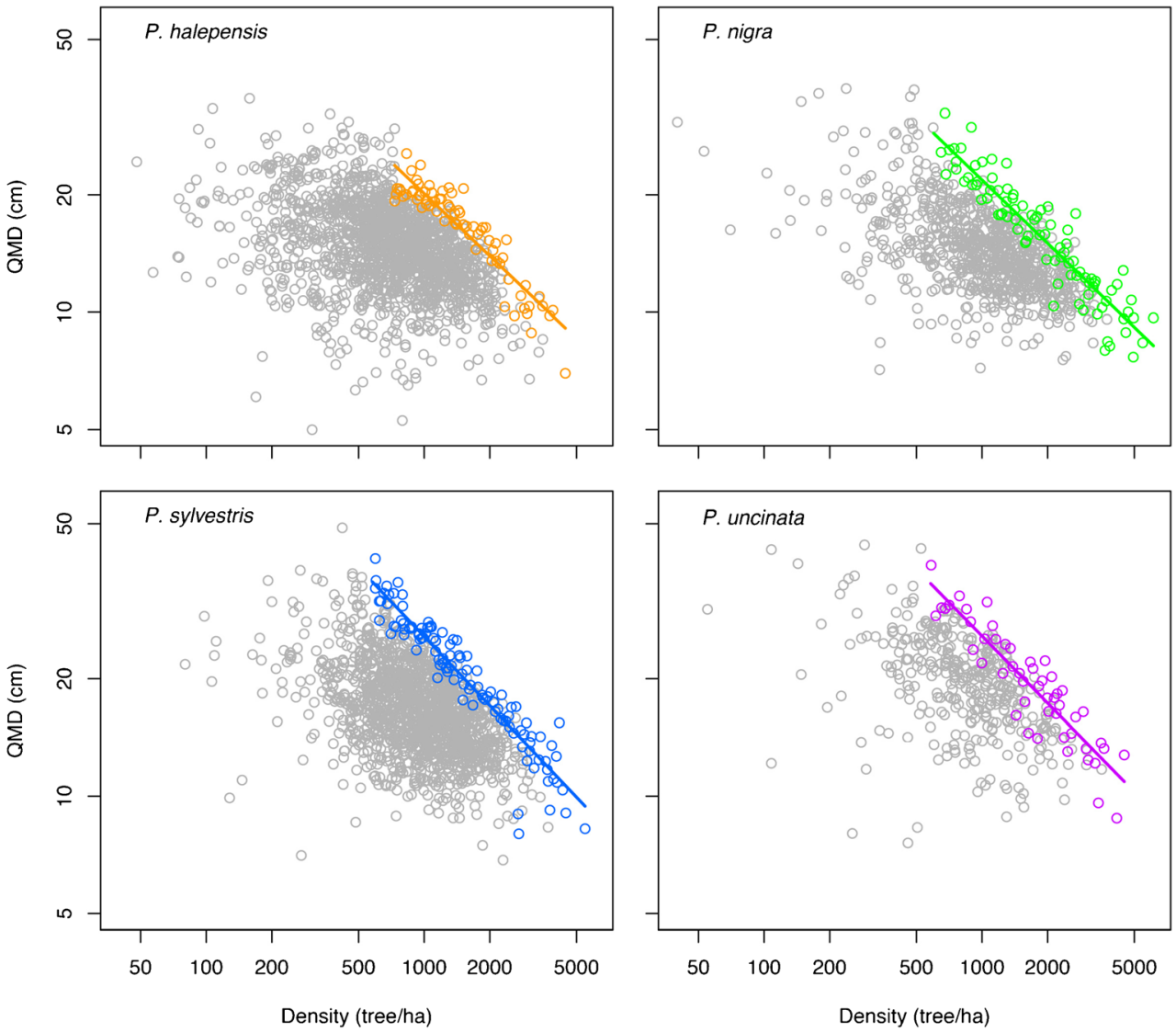

transform the slope results (calculating the inverse) for their comparison with other studies that used tree density as dependent variable.

The intercepts and slopes estimated by the STL analysis were compared among the pine species with confidence intervals (CI) of $95 \%$ assuming a normal distribution. Since intercept and slope estimates were largely dependent, the STL intercepts at the centred density were used and showed for comparison purposes (Fig. 3). Using intercepts at centred density instead of values of $\log (k)$, the impact of slope variations was minimized when the intercepts across species or across plots were compared (see below). Therefore, the centred tree

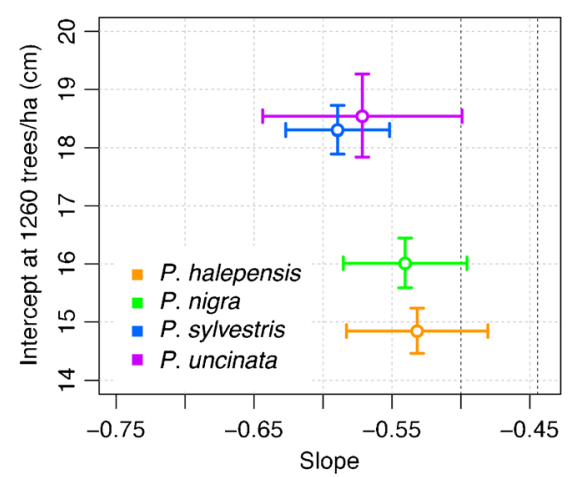

Fig. 3 Relationship between slope and intercept at midpoint density for each of the four species. Error bars represent $95 \%$ confidence intervals density as the arithmetic mean of the four mean densities per species $\left(N_{\mathrm{m}, \mathrm{i}}\right)$ was calculated. For each species $(i)$, the mean density was calculated by using logarithmic values with the following formula:

$$
N_{\mathrm{m}, \mathrm{i}}=\left(N_{\max , \mathrm{i}}+N_{\min , \mathrm{i}}\right) / 2 .
$$

where $N_{\text {max,i }}$ and $N_{\text {min,i }}$ are, respectively, maximum and minimum logarithmic tree density for species $i$.

STLs were recalculated to show possible impacts of mean annual temperature and mean annual precipitation on the STL of different species. For each species, the averages of mean temperature and mean precipitation of all plots were used to differentiate subsets of plots growing under higher or lower conditions of temperature and precipitation. The new species' STLs were calculated by using these subsets of plots. The new coefficients of the STLs were estimated and tested by using the $l m$ function in $R$ as previously done.

Additional calculations were performed to analyse the results. The De Martonne aridity index (De Martonne 1926) was used to estimate the conditions of aridity in which each species grows. The aridity index was calculated for each plot and then averaged for each species. We also studied the effect of stand structure over STLs. Plots were classified as even aged or uneven aged, with even-aged plots defined as those with trees differing 5 years maximally and uneven aged with trees differing more than 5 years. Age data was only available for a fraction of the plots used. We used the maximum difference of 
Table 2 Slopes and intercepts at midpoint density (see Fig. 4) calculated by each species selfthinning line with its standard error (SE)

\begin{tabular}{llllllll}
\hline Species & Slope $\pm \mathrm{SE}$ & $\begin{array}{l}t \text { value } \\
\text { (to }-1 / 2)\end{array}$ & $\begin{array}{l}t \text { value } \\
\text { (to }-4 / 9)\end{array}$ & log(Int \pm SE) & $\begin{array}{l}\text { Int } \\
{[\mathrm{cm}]}\end{array}$ & $\begin{array}{l}\text { Int } 1 \\
{[\mathrm{~cm}]}\end{array}$ & $\begin{array}{l}\text { Slope } \\
(\mathrm{MA})\end{array}$ \\
\hline P. halepensis & $-0.533 \pm 0.026$ & -1.267 & -3.409 & $1.172 \pm 0.006$ & 14.85 & 799.86 & -1.777 \\
P. nigra & $-0.540 \pm 0.023$ & -1.768 & -4.195 & $1.204 \pm 0.006$ & 16.01 & 913.09 & -1.787 \\
P. sylvestris & $-0.589 \pm 0.019$ & -4.655 & -7.548 & $1.263 \pm 0.005$ & 18.31 & 1505.58 & -1.647 \\
P. uncinata & $-0.571 \pm 0.037$ & -1.938 & -3.444 & $1.268 \pm 0.009$ & 18.54 & 1333.72 & -1.665 \\
\hline
\end{tabular}

For each species, $t$ values of slopes are showed for their comparison to hypothetical values of $-1 / 2$ and $-4 / 9$. Also, retransformed intercepts at midpoint density (Int) and at 1 tree ha $^{-1}$ (Int 1) are showed. The Slope (MA) column shows the slopes calculated by using the major axis method and the tree density as dependent variable
QMD calculated from even-aged plots with age data as a threshold to classify all plots as even or uneven aged.

\section{Results}

\subsection{Across species comparison of self-thinning line}

The minimum tree density threshold where self-thinning take place was 732 trees ha ${ }^{-1}$ for $P$. halepensis, 600 trees ha ${ }^{-1}$ for P. nigra, 579 trees ha $^{-1}$ for $P$. sylvestris and 581 trees ha ${ }^{-1}$ for P. uncinata.

The STL slopes of $P$. sylvestris was significantly steeper than the range of expected values (between $-1 / 2$ and $-4 / 9$ ), whereas $P$. uncinata, $P$. nigra and $P$. halepensis did not show significant differences (Fig. 3). Slopes did not show significant differences among species. Intercepts showed significant differences between all species, except between $P$. sylvestris and P. uncinata (Table 2, Fig. 3).

The intercept increased for species growing on higher altitudes described by higher precipitation and colder conditions. The same species order was found by using the aridity index (Table 3).

\subsection{Effects of climate on the self-thinning line}

STLs estimated from plots growing in areas with higher average temperatures did not significantly differ from STLs estimated from plots growing in areas with lower average temperatures, except for P. sylvestris (Table 4, Fig. 4). The STL of $P$. sylvestris growing in colder conditions had a significantly

Table 3 Aridity index of the four species

\begin{tabular}{lllll}
\hline Species & Min & Max & Avg & SD \\
\hline P. halepensis & 14.3 & 24.4 & 22.2 & 5.0 \\
P. nigra & 16.3 & 51.4 & 30.7 & 3.7 \\
P. sylvestris & 24.4 & 80.6 & 44.0 & 6.5 \\
P. uncinata & 43.6 & 82.8 & 60.3 & 8.4 \\
\hline
\end{tabular}

Min minimum value, Max maximum value, Avg average value, $S D$ standard deviation higher intercept and steeper slope. Although not significantly different, the STLs of P. nigra and $P$. uncinata seemed to have higher intercepts and steeper slopes when estimated under colder conditions.

Results showed significant differences among STLs estimated from plots with higher annual precipitations compared to STLs estimated from plots with lower annual precipitations for P. halepensis and P. uncinata (Table 4, Fig. 4). $P$. halepensis' STL showed a higher intercept when growing in wetter conditions. Instead, $P$. uncinata's STL had a higher intercept when growing in dryer conditions. $P$. nigra seemed to have higher intercepts and steeper slopes when it grows under wetter conditions, but the differences were not significant.

\subsection{Effects of structure on the self-thinning lines}

The maximum QMD difference calculated for even-aged plots was $28.6 \mathrm{~cm}$. Using this difference, we estimated that $80 \%$ of pine stands in Catalonia are even aged. The comparison between STLs' slopes of even-aged and uneven-aged plots did not show significant differences for any species (Fig. 4). Only intercepts of $P$. sylvestris and $P$. uncinata estimated for uneven-aged plots were significantly higher than the intercepts estimated from even-aged plots. STLs estimated by using all plots were not significantly different than STLs estimated by using even-aged plots with also the exception of a higher intercept of STLs estimated by using all plots of $P$. sylvestris and P. uncinata.

\section{Discussion}

The four studied pine species occupied different altitudes and climate zones in Catalonia, expressing their differences in habitat requirements (Castro 1998). In this study, we explored the effects of annual mean temperature and precipitation on growth and stand development and on self-thinning lines in particular. While valuable, this approach cannot trace more subtle climate impacts, such as, for example, late summer rainfall or other aspects of the regional climate, which are 


\section{$P$. halepensis}
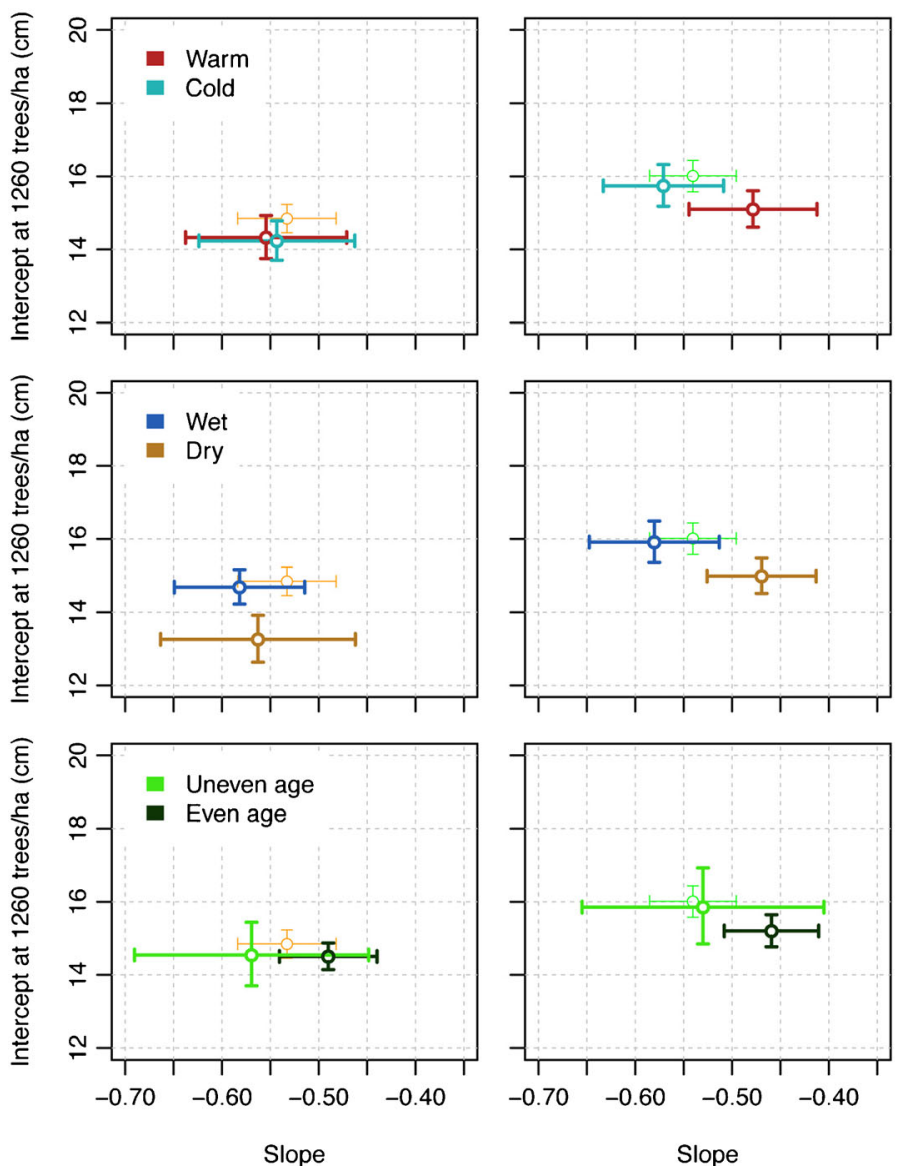

Fig. 4 Comparison of self-thinning lines for four pine species in Catalonia growing in different climate conditions and with different stand structures. The slope and the intercept at centred density of each species is represented besides the slope and the intercept at centred

sometimes considered important determinants of stand growth and development (Andreu et al. 2007). While the self-thinning law was originally described for even-aged plant populations, we quantified self-thinning lines by using both even-aged and uneven-aged stands. We analysed how the selection of evenaged plots would have affected STLs. We found that only the intercept of $P$. sylvestris and $P$. uncinata showed significant differences. However, slopes tend to be flatter, and the significant differences found in P. sylvestris' STL slope compared with the hypothesis of $-1 / 2$ would disappear. From this, we conclude that uneven-aged stands may achieve higher intercepts for their STL than even-aged stands, implying that they can accumulate more biomass, which can be important for managing forest for biomass or carbon accumulation.

The theoretical predictions of STL slopes of $-1 / 2$ and $-4 / 9$, i.e. predictions that are based on allometric scaling (e.g. Enquist et al. 1998), and assumptions for leaf distributions within trees (Zeide and Pfeifer 1991; Sterck and Schieving 2007; Duursma et al. 2010) were tested. Species had slopes that were similar to $-1 / 2$, but they all differed from $-4 / 9$. Only
P. sylvestris
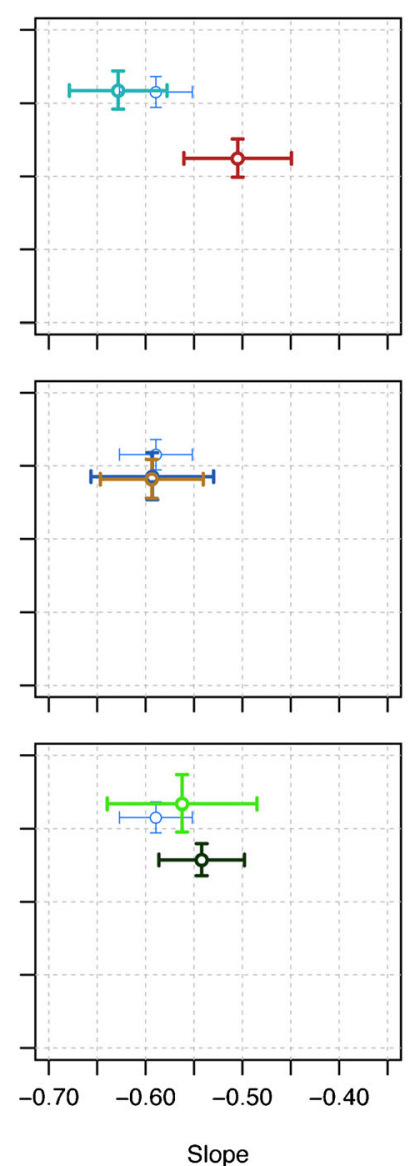

P. uncinata
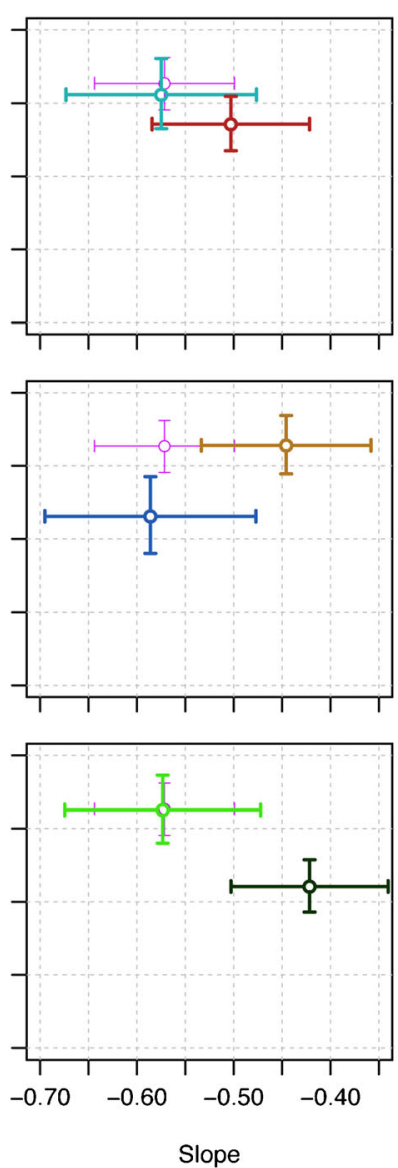

density estimated for each species growing in climate extremes (from top to bottom species mean temperature, precipitation, and structure). Thin lines represent species STL

P. sylvestris had a slope significantly steeper than $-1 / 2$. The slope obtained for $P$. sylvestris by using the major axis method and tree density as dependent variable $(-1.647)$ is flatter than values reported from other studies conducted with this species in the same (-1.815 (Palahi et al. 2003)) or nearby regions of Spain (-1.830 (del Rio et al. 2001)). This slope is also flatter than most of the studies conducted in regions with more favourable climates (e.g. -1.87 in the Italian Alps (Vacchiano et al. 2008), between -1.750 and -1.762 in Austria (Vospernik and Sterba 2015), with the exception of Germany (between -1.445 and -1.695 according to Pretzsch and Biber (2005)). This shows that slopes might be site or context dependent, and given the strong dependency of slopes on intercepts of STL, the ecological value of comparing slopes is rather uncertain. For species comparisons, we therefore considered mid-density estimates of the QMD, thus reducing possible implications of intercept-slope interdependencies. As mentioned before, the use of uneven-aged plots could explain it, but additional research is required to clarify the steeper selfthinning slope observed for P. sylvestris. There may be other 
Table 4 Slopes and intercepts at midpoint density (see Fig. 4) calculated by each species selfthinning line under climate extremes of temperature and precipitation with its standard error (SE)

\begin{tabular}{lllllllr}
\hline Species & Climate & $n_{\mathrm{t}}$ & $n_{\mathrm{st}}$ & Slope $\pm \mathrm{SE}$ & $\log (\mathrm{Int} \pm \mathrm{SE})$ & Int [cm] & Int $1[\mathrm{~cm}]$ \\
\hline P. halepensis & High temperature & 852 & 49 & $-0.554 \pm 0.042$ & $1.156 \pm 0.009$ & 14.32 & 906.55 \\
& Low temperature & 824 & 45 & $-0.543 \pm 0.041$ & $1.153 \pm 0.008$ & 14.23 & 828.92 \\
& High precipitation & 891 & 52 & $-0.582 \pm 0.034$ & $1.167 \pm 0.007$ & 14.69 & 1141.47 \\
& Low precipitation & 785 & 45 & $-0.563 \pm 0.051$ & $1.123 \pm 0.011$ & 13.26 & 893.54 \\
P. nigra & High temperature & 514 & 55 & $-0.478 \pm 0.034$ & $1.179 \pm 0.007$ & 15.10 & 540.91 \\
& Low temperature & 355 & 65 & $-0.571 \pm 0.032$ & $1.197 \pm 0.008$ & 15.74 & 1127.14 \\
& High precipitation & 395 & 57 & $-0.580 \pm 0.034$ & $1.202 \pm 0.008$ & 15.91 & 1222.83 \\
& Low precipitation & 474 & 61 & $-0.469 \pm 0.029$ & $1.176 \pm 0.007$ & 14.99 & 502.45 \\
Pylvestris & High temperature & 741 & 71 & $-0.505 \pm 0.028$ & $1.217 \pm 0.007$ & 16.49 & 720.43 \\
& Low temperature & 809 & 69 & $-0.628 \pm 0.026$ & $1.264 \pm 0.006$ & 18.35 & 2018.97 \\
& High precipitation & 659 & 63 & $-0.593 \pm 0.032$ & $1.248 \pm 0.008$ & 17.70 & 1496.44 \\
& Low precipitation & 891 & 74 & $-0.594 \pm 0.027$ & $1.246 \pm 0.007$ & 17.63 & 1496.69 \\
& High temperature & 209 & 46 & $-0.503 \pm 0.042$ & $1.241 \pm 0.009$ & 17.43 & 750.74 \\
& Low temperature & 190 & 34 & $-0.575 \pm 0.050$ & $1.261 \pm 0.012$ & 18.23 & 1345.19 \\
& High precipitation & 146 & 33 & $-0.586 \pm 0.056$ & $1.221 \pm 0.014$ & 16.62 & 1333.12 \\
& Low precipitation & 253 & 43 & $-0.446 \pm 0.045$ & $1.269 \pm 0.010$ & 18.56 & 521.06 \\
\hline
\end{tabular}

Retransformed intercepts at midpoint density (Int) and at 1 tree ha ${ }^{-1}$ (Int 1$)$ are showed. Total number of plots $\left(n_{\mathrm{t}}\right)$; number of plots in self-thinning phase $\left(N_{\mathrm{st}}\right)$ reasons for a lack of more intra-specific differences, i.e. the limited number of plots per species, the limited environmental range occupied by each species or possible confounding factors such as differences in management history across plots (Luyssaert et al. 2011) or in nutrient availability (Morris 2003; Fernandez-Martinez et al. 2014).

The intercepts estimated here presented significant differences between most of the species (Fig. 3, Table 2). Those differences in intercepts between species might partially result from the different climate envelops occupied by those species (Table 3). In line with these results, other studies suggest that the intercept of the self-thinning lines is dependent on the site index (Palahi et al. 2003). The variability of slopes seems less affected by climatic conditions than the variability of intercepts (Fig. 4, Table 4). Variability in STLs may also occur due to methodological effects: low sample size (number of plots, as seen from the high variance in results by Pretzsch and Biber (2005)). Studies by using different methodologies, such as selection of different quantiles, may not be comparable. We believe that our results slightly underestimated the intercept (see Fig. 2) because we used the $5 \%$ of plots with the highest QMD in each tree density interval. The estimated intercept would be higher if we had selected a lower percentage of plots. But in this case, the sample size used to estimate the STL would be lower. A similar trade-off was identified by Vospernik and Sterba (2015) by using quantile regression. Thus, the percentage of selected plots must be high enough to estimate the slope with a reasonably low confidence interval but low enough to estimate the 'correct' intercept. Obviously, this problem is less severe when the proportion of plots in self-thinning phase is high because the standard variation will be smaller or when the total number of plots is high because then we can use a higher quantile and obtain the same standard deviation.

Water stress is known to be a major growth-limiting factor in lowland Mediterranean areas (Roda et al. 1999). Therefore, the species at the lowest altitudes where the warmest and driest conditions occur were expected to suffer from water stress and consequently to have smaller intercepts than other species. At the higher altitudinal end, the pattern may be reversed when forest stands are not limited by water scarcity (Martínez-Vilalta et al. 2008). Our results are largely in line with these expectations (Fig. 4). At the lowest altitude, P. halepensis had the lowest STL intercept and its magnitude appeared to be limited by low precipitation. For the species that occurred at higher altitudes that are less drought stressed, the intercepts increased and their magnitude seem to be limited by high temperatures (e.g. P. sylvestris). For P. uncinata, which occurred at the highest altitudes, the intercept was not significantly different from $P$. sylvestris, but the high precipitations appeared to be the limiting factor for the intercept. P. sylvestris is close to the southern (and dry) limit of its distribution in Catalonia. Previous studies have detected drought-induced decline in several populations of this species in the study area (e.g. VilaCabrera et al. 2013). However, we found size limitations due to warm conditions but not due to precipitation in this species.

STLs have already been used to estimate the effects of land use on carbon cycle (Luyssaert et al. 2011). Our study shows how STLs may be used to predict carbon stocks in living biomass depending on species and climate conditions. For example, we can predict that increases in temperature may reduce the potential carbon stock in P. sylvestris forests. 
Instead, $P$. halepensis seems to be more adapted to high temperatures and therefore less affected by increases in temperature, but it is more sensitive to water scarcity. Our results suggest that a lower precipitation could reduce potential carbon stocks in lowland pines but could be beneficial for $P$. uncinata growing in high altitudes. In line with this result, Vayreda et al. (2012b) identified reductions on carbon accumulations in Spanish forests due to recent warming and due to lower water availability. Using the STLs, we can identify which species are likely to grow to larger sizes under new conditions and promote these species as a climate change adaptation strategy. The utilization of such species will likely enhance the carbon storage in forests and contribute to climate change mitigation. With the study presented here, we cannot estimate carbon stocks increment under specific climate change scenarios because we do not know the exact shape of the relationship between STL slopes and intercepts and climate. Future work should be directed at relating changes in STLs to changes in carbon content under future climate scenarios.

Acknowledgments This paper was based on the MSc thesis of the first author, written as partial fulfilment for the MSc degree in Forest and Nature Conservation at Wageningen University, as well as for the Erasmus Mundus MSc programme in European Forestry. Additional funding was provided by the EU-FORMIT programme on 'Forest management strategies to enhance the mitigation potential of European forests' (EU grant no. 311970 FORMIT).

The authors want to thank the anonymous reviewers for the useful comments provided which contributed to the quality of this study.

Contribution of the co-authors Sterk: conceptualizing the analysis, supervising the work and editing the paper.

Vayreda: raw data preparation.

Martinez-Vilalta: raw data preparation and editing the paper.

Mohren: conceptualizing the analysis, supervising the work and editing the paper.

\section{Compliance with ethical standards}

Funding This paper has been founded partly by an Erasmus Mundus scholarship given to the first author and partly by the EU-FORMIT programme on 'Forest management strategies to enhance the mitigation potential of European forests' (EU grant no. 311970 FORMIT).

Open Access This article is distributed under the terms of the Creative Commons Attribution 4.0 International License (http:// creativecommons.org/licenses/by/4.0/), which permits unrestricted use, distribution, and reproduction in any medium, provided you give appropriate credit to the original author(s) and the source, provide a link to the Creative Commons license, and indicate if changes were made.

\section{References}

Andreu L, Gutierrez E, Macias M, Ribas M, Bosch O, Camarero JJ (2007) Climate increases regional tree-growth variability in Iberian pine forests. Glob Chang Biol 13:804-815. doi:10.1111/j.13652486.2007.01322.x

Anfodillo T, Carrer M, Simini F, Popa I, Banavar JR, Maritan A (2013) An allometry-based approach for understanding forest structure, predicting tree-size distribution and assessing the degree of disturbance. Proc R Soc B-Biol Sci 280:8. doi:10.1098/rspb.2012.2375

Barbero M, Loisel R, Quezel P, Richardson DM, Romane F (1998) Pines of the Mediterranean Basin. In: Richardson DM (ed) Ecology and biogeography of Pinus. Cambridge University Press, Cambridge, pp. $153-170$

Begon M, JL Harper, CR Townsend (1996) Ecology: individuals, populations and communities. Oxford, UK. pp. 156-162

Bonan GB (2008) Forests and climate change: forcings, feedbacks, and the climate benefits of forests. Science 320:1444-1449. doi:10.1126/science. 1155121

Castro EB (1998) Los bosques ibéricos: una interpretación geobotánica. GeoPlaneta, Editorial, S. A

De Martonne E (1926) Aréisme et indice artidite. Comptes Rendus de L'Acad Sci 182:1395-1398

del Rio M, Montero G, Bravo F (2001) Analysis of diameter-density relationships and self-thinning in non-thinned even-aged scots pine stands. For Ecol Manag 142:79-87. doi:10.1016/s0378-1127(00) 00341-8

Deng JM, Wang GX, Morris EC, Wei XP, Li DX, Chen BM, Zhao CM, Liu J, Wang Y (2006) Plant mass-density relationship along a moisture gradient in north-west China. J Ecol 94:953-958. doi:10.1111/ j.1365-2745.2006.01141.x

Duursma RA, Makela A, Reid DEB, Jokela EJ, Porte AJ, Roberts SD (2010) Self-shading affects allometric scaling in trees. Funct Ecol 24:723-730. doi:10.1111/j.1365-2435.2010.01690.x

Enquist BJ, Brown JH, West GB (1998) Allometric scaling of plant energetics and population density. Nature 395:163-165

Fernandez-Martinez M, Vicca S, Janssens IA, Sardans J, Luyssaert S, Campioli M, Chapin FS, Ciais P, Malhi Y, Obersteiner M, Papale D, Piao SL, Reichstein M, Roda F, Penuelas J (2014) Nutrient availability as the key regulator of global forest carbon balance. Nat Clim Chang 4:471-476. doi:10.1038/nclimate2177

Kempeneers P, Sedano F, Seebach L, Strobl P, San-Miguel-Ayanz J (2011) Data fusion of different spatial resolution remote sensing images applied to forest-type mapping. IEEE Trans Geosci Remote Sens 49:4977-4986. doi:10.1109/TGRS.2011.2158548

Lonsdale WM (1990) The self-thinning rule: dead or alive? Ecology 71: 1373-1388. doi:10.2307/1938275

Luyssaert S, Hessenmoller D, von Lupke N, Kaiser S, Schulze ED (2011) Quantifying land use and disturbance intensity in forestry, based on the self-thinning relationship. Ecol Appl 21:3272-3284

Martínez-Vilalta J, López BC, Adell N, Badiella L, Ninyerola M (2008) Twentieth century increase of scots pine radial growth in NE Spain shows strong climate interactions. Glob Chang Biol 14:2868-2881. doi: $10.1111 / j .1365-2486.2008 .01685 . x$

Morris CE (2003) How does fertility of the substrate affect intraspecific competition? Evidence and synthesis from self-thinning. Ecol Res 18:287-305. doi:10.1046/j.1440-1703.2003.00555.x

Ninyerola M, Pons X, Roure JM (2000) A methodological approach of climatological modelling of air temperature and precipitation through GIS techniques. Int J Climatol 20:1823-1841. doi:10.1002/10970088(20001130)20:14<1823::aid-joc566>3.0.co;2-b

Palahi M, Pukkala T, Miina J, Montero G (2003) Individual-tree growth and mortality models for scots pine (Pinus sylvestris L.) in north-east Spain. Ann For Sci 60:1-10. doi:10.1051/forest:2002068

Pan YD, Birdsey RA, Fang JY, Houghton R, Kauppi PE, Kurz WA, Phillips OL, Shvidenko A, Lewis SL, Canadell JG, Ciais P, Jackson RB, Pacala SW, McGuire AD, Piao SL, Rautiainen A, Sitch S, Hayes D (2011) A large and persistent carbon sink in the world's forests. Science 333:988-993. doi:10.1126/science.1201609 
Pretzsch H (2006) Species-specific allometric scaling under self-thinning: evidence from long-term plots in forest stands. Oecologia 146:572583. doi:10.1007/s00442-005-0126-0

Pretzsch H, Biber P (2005) A re-evaluation of Reineke's rule and stand density index. For Sci 51:304-320

Reineke LH (1933) Perfecting a stand-density index for even-aged forests. J Agric Res 46:627-638

Roda F, Retana J, Gracia CA, Bellot (1999) Ecological Studies; Ecology of Mediterranean evergreen oak forests. In: Roda R, Retana J, Gracia CA, Bellot J (eds) Ecological Studies; Ecology of Mediterranean evergreen oak forests. Springer-Verlag, Heidelberger Platz 3, D-1000 Berlin, Germany; Springer-Verlag New York, Inc., 175 Fifth Avenue, New York, New York 10010, USA, pp. xxi +373 p

Ryan MG, Yoder BJ (1997) Hydraulic limits to tree height and tree growth. Bioscience 47:235-242. doi:10.2307/1313077

Solbrig OT, White J, Lloyd DG, Abrahamson WG, Cook R, Snaydon RW, Sarukhán J (1980) Demography and evolution in plant populations. Blackwell, Oxford

Sterck FJ, Schieving F (2007) 3-D growth patterns of trees: effects of carbon economy, meristem activity, and selection. Ecol Monogr 77: 405-420. doi:10.1890/06-1670.1

Vacchiano G, Motta R, Long JN, Shaw JD (2008) A density management diagram for scots pine (Pinus sylvestris L.): a tool for assessing the forest's protective effect. For Ecol Manag 255:2542-2554. doi:10.1016/j.foreco.2008.01.015

Vayreda J, Gracia M, Canadell JG, Retana J (2012a) Spatial patterns and predictors of forest carbon stocks in western Mediterranean. Ecosystems 15:1258-1270. doi:10.1007/s10021-012-9582-7
Vayreda J, Martinez-Vilalta J, Gracia M, Retana J (2012b) Recent climate changes interact with stand structure and management to determine changes in tree carbon stocks in Spanish forests. Glob Chang Biol 18:1028-1041. doi:10.1111/j.1365-2486.2011.02606.x

Vila-Cabrera A, Martinez-Vilalta J, Galiano L, Retana J (2013) Patterns of Forest decline and regeneration across scots pine populations. Ecosystems 16:323-335. doi:10.1007/s10021012-9615-2

Vospernik S, Sterba H (2015) Do competition-density rule and self-thinning rule agree? Ann For Sci 72:12. doi:10.1007/s13595-014-0433-x

Weller DE (1987) A reevaluation of the $-3 / 2$ power rule of plant selfthinning. Ecol Monogr 57:23-43. doi:10.2307/1942637

West GB, Brown JH, Enquist BJ (1997) A general model for the origin of allometric scaling laws in biology. Science 276:122-126. doi:10.1126/science.276.5309.122

Westoby M (1984) The self-thinning rule. Adv Ecol Res 14:167-225. doi:10.1016/s0065-2504(08)60171-3

Yoda K, Kira T, Ogawa H, Hozumi K (1963) Self thinning in overcrowded pure stands under cultivated and natural conditions. J Biol, Osaka City Univ 14:106-129 citeulike-article-id:2990691

Zeide B, Pfeifer P (1991) A method for estimation of fractal dimension of tree crowns. For Sci 37:1253-1265

Zhang QA, Zhang L, Weiner J, Tang JJ, Chen X (2011) Arbuscular mycorrhizal fungi alter plant allometry and biomass-density relationships. Ann Bot 107:407-413. doi:10.1093/aob/mcq249 